marrow recovery refer, therefore, solely to the regression of leukaemic blast cells. By three weeks only $65.6 \%$ of the patients in the Concord trial and $67.5 \%$ in the UKALL I trial but $80.4 \%$ in the UKALL II trial had less than $5 \%$ of blast cells in the marrow. A higher proportion of UKALL II marrow specimens, however, showed severely decreased cellularity at three weeks, though this finding was not sufficiently quantitative to be analysed further. At six and 13 weeks there was no significant difference between the bone marrow regression rates in the three trials.

\section{Discussion}

The validity of comparing trials not carried out simultaneously is often called into question but it seems unlikely that this caused any serious bias in this instance. In particular there was no reason to suppose that the methods of measurement and management had significantly altered within the four years under study.

Our evidence shows that the addition of colaspase during the first week of the remission induction regimen of vincristine and prednisolone causes a significantly increased suppression of both normal and leukaemic cells in the bone marrow, as shown by the increased blast-cell regression and lower blood neutrophil and platelet counts. The induced neutropenia resulted in an increased liability to serious and fatal infections to which the immunosuppressive effect of colaspase (Maral et al., 1970), the alteration of neutrophil function by asparagine depletion (Strauss et al., 1970; Skeel et al., 1971), or an effect of colaspase on the gut mucosa might also have contributed. The clinical importance of the added period of thrombocytopenia is difficult to assess, since bleeding was largely prevented by platelet transfusion.

Colaspase could cause marrow depression either directly or by potentiating the myelotoxicity of vincristine. A potentiating effect might be mediated by the liver, since the hepatotoxicity of colaspase (Land et al., 1970; Pratt and Johnson, 1971) could interfere with drug catabolism, or might directly affect the susceptibility of bone marrow cells to vincristine. Alternatively deprivation of asparagine may simply retard the proliferation rate of the regenerating haemopoietic cells. The absence of significant neurotoxicity and alopecia from vincristine in the UKALL II trial is rather against a hepatic mechanism of vincristine potentiation and favours the bone marrow as the site of action.

Notwithstanding its observed toxicity, colaspase significantly increased the rate of blast-cell regression in the UKALL II trial. It is possible that this initial reduction of leukaemic cells might lead to an increased duration of remission (Jones and Holland, 1973), but this could not be tested in these trials because of the differences in subsequent therapy. An increased death rate during remission induction, however, is not an acceptable price to pay for this theoretical advantage. It is probable that a similar long-term effect could be obtained by giving colaspase at a later phase in treatment. It is therefore recommended that colaspase should not be given during the induction phase of treatment in A.L.L. until there is evidence of marrow regeneration or until it becomes clear that other agents are failing to induce remission.

We wish to thank all the members of the M.R.C. Working Party (Chairman, Professor J. H. Hutchison) who contributed to these trials, and particularly Drs. Elizabeth Innes, Dorothy Mainwaring, and John Mantin. Miss Mollie Gilham and Miss Helen Totman gave valuable help in the collection of data.

\section{References}

Aur, R. J. A., et al. (1971). Blood, 37, 272.

Holland, J. F., and Glidewell, O. (1972). Cancer (Philadelphia), 30, 1480 Jones, B., and Holland, J. F. (1973). Blood, 42, 1015

Land, V. J., et al. (1970). Cancer (Philadelphia), 30, 339.

Maral, R., et al. (1970). Recent Results in Cancer Research, 33, 160.

Medical Research Council (1971). British Medical fournal, 4, 189.

Medical Research Council (1973). British Medical fournal, 2, 381.

Oettgen, H. F., et al. (1970). Recent Results in Cancer Research, 33, 219.

Pratt, C. B., and Johnson, W. W. (1971). Cancer (Philadelphia), 28, 361.

Skeel, R. T., Yankee, R. A., and Henderson, E. S. (1971). Fournal of Laboratory and Clinical Medicine, 77, 975.

Strauss, R. R., et al. (1970). Cancer Research, 30, 480.

\title{
Hepatitis B Antigen in Viral Hepatitis in West London
}

\author{
L. J. FARROW, S. G. LAMB, N. F. COGHILL, R. L. LINDON, JILL PREECE, \\ A. J. ZUCKERMAN, J. S. STEWART
}

British Medical fournal, 1974, 3, 83-86

\section{Summary}

During the first 12 months of a total population survey 249 patients were seen with viral hepatitis. A total of 215

West Middlesex Hospital, Isleworth, Middlesex TW7 6AF

L. J. FARROW, M.B., M.R.C.P., Senior Medical Registrar (Present address: Watford General Hospital, Watford, Herts)

N. F. COGHILL, M.B., F.R.C.P., Consultant Physician

J. S. STEWART, M.D., M.R.C.P., Consultant Physician

South Middlesex Hospital, Isleworth, Middlesex TW7 7LN

S. G. LAMB, M.B., D.P.H., Physician in Infectious Diseases and Honorary Senior Lecturer in Communicable Diseases, University College Hospita Medical School

Department of Health, London Borough of Hounslow, Hounslow, Middlesex TW3 3EL

R. L. LINDON, F.F.C.M., D.P.H., Medical Officer of Health

Department of Microbiology, London School of Hygiene and Tropical Medicine, London WC1E 7HT

A. J. ZUCKERMAN, M.D., D.sC., Professor of Virology

JILL PREECE, Research Assistant of these were tested for hepatitis $\mathrm{B}$ antigen (HB Ag) by radioimmunoassay and $32(15 \%)$ were positive.

More than five times as many men (27) as women (5) were HBAg positive and 19 of the men were between the ages of 20 and 39 years. There were only four drug addicts among those tested, two of whom were positive, as were two of the four patients who were tattooed.

Sixty out of 86 children (under 15 years) were tested for HBAg and none was positive.

\section{Introduction}

Australia antigen, now referred to as hepatitis B antigen ( $\mathrm{HBAg}$ ) in view of its association with hepatitis $B$ infection provides a reliable serological marker of an agent which causes this type of infection (World Health Organization, 1973):

In Great Britain the reported prevalence of HBAg in patients admitted to hospital with hepatitis has varied between $4 \%$ (Ross 
and McMichael, 1970) and 40\% (Cossart et al., 1969). Ross and McMichael examined samples of serum from patients admitted consecutively to a Glasgow hospital, over half of whom were under the age of 15. Cossart et al., tested patients admitted consecutively from a predominantly urban community in West London, but only one of the 27 patients tested was under 15 years of age. Results were not classified epidemiologically in either of these reports. In another group studied in West London Farrow et al. (1970) found 13 (33\%) out of 39 patients positive for HBAg; none of these patients were under 15 years old.

Since 15 June 1968 infective jaundice has been notifiable throughout England and Wales under the Public Health (Infective Jaundice) Regulations. Notification, however, reflects an initial diagnostic impression, which in some cases may not be confirmed by subsequent investigation. Such reports are not always revised. Notifications to the Registrar General form the basis of national statistics on hepatitis, and it is these that are most often quoted.

We decided to determine the incidence of HBAg among all patients accepted as having viral hepatitis* within a defined area, whether or not they were admitted to hospital. At the same time we examined the epidemiology of viral hepatits with special reference to its distribution in the community, possible modes of spread, and factors affecting severity in relation to the presence of HBAg.

A 12-month pilot study was undertaken to assess the value of such an investigation. The most interesting feature of this study was a low incidence $(14 \%)$ of HBAg in sporadic hepatitis in an urban area, which contrasted with previous reports from London (Cossart et al., 1969; Farrow et al., 1970). The results might not have been representative, however, because the study lasted only one year and was confined to the London Borough of Hounslow with a population of only 206,000 .

It therefore seemed appropriate to conduct a three-year prospective survey of all suspected cases of hepatitis in a larger urban population, namely that of the three London Boroughs of Hounslow, Ealing, and Richmond-a total of 706,000 people. We report here the results of the first 12 months of the survey.

\section{Plan of Three-year Survey}

To achieve a more comprehensive survey with early detection of cases and collection of serum samples a field team was appointed consisting of a full-time doctor and a health visitor supported by a part-time secretary. From the start the survey was planned as a collaborative community study between the general practitioners, the local health authorities, and the South Middlesex and West Middlesex Hospitals. Other hospitals also helped by reporting cases and by providing information and samples of serum from their patients admitted from the area under study. The field team received information about patients from the local health authorities and often directly from the general practitioners. Some patients were able to trace contacts, and schools also co-operated.

\section{Patients}

During the first 12 months of the survey there were 310 patients who had an illness notified as infective jaundice. After referral 61 patients were excluded from the survey. These comprised 18 with either biliary tract or pancreatic disease, three with drug jaundice, four with chronic liver disease, and one with Gilbert's disease. Eight patients had infectious mononucleosis. Twentyseven patients who presented with febrile or alimentary symptoms were found not to have evidence of hepatitis.

A diagnosis of viral hepatitis was accepted on clinical and biochemical grounds in 249 patients, an incidence of 36 per 100,000 population. The vast majority of these patients gave a

*Viral hepatitis includes both type A and type B hepatitis. history of a febrile or gastrointestinal illness and dark urine followed by jaundice. In $15(6 \%)$ cases, however, jaundice was not confirmed. Seven of these patients were detected as contacts of patients who were jaundiced because of viral hepatitis.

The patients were allocated to the following arbitrary epidemiological groups based on the history of the possible mode of exposure to infection: (a) Ingestion-definite close contact with another case of jaundice thought to be due to viral hepatitis between 15 and 60 days before the onset of symptoms; (b) parenteral-known history of skin puncture between 15 days and six months before the onset of symptoms; (c) unknownno known history of exposure to either ingestion or parenteral infection; $(d)$ equivocal-history of exposure to both ingestion and parenteral infection within the relevant periods. This grouping seemed to be a reasonable device to gain more insight into the aetiological agents.

\section{Methods}

All patients on whom the field team received information were interviewed by the health visitor using a questionnaire developed during the pilot study. The visiting doctor made a clinical assessment and obtained blood for biochemical tests to support the diagnosis and for serological tests. Epidemiological data were collected at the time of the initial interview and were transferred to punch cards. The patients were seen initially about once a week for clinical assessment and collection of further blood samples and then less often until they had recovered both clinically and biochemically and until any antigenaemia had cleared.

Serum bilirubin (Malloy and Evelyn, 1937), alkaline phosphatase (Marsh et al., 1959), and alanine aminotransferase (Mohun and Cook, 1957) were measured by standard methods. The HBAg was detected by a sandwich-type radioimmunoassay technique (Ausria ${ }^{125}$ ) as previously used by Reed et al. (1973), which combines the specificity of antigen-antibody reaction with the sensitivity of radioisotope detection and is now accepted as the most sensitive technique available (World Health Organization, 1973).

\section{Results}

HBAg was found in $32(15 \%)$ of the 215 patients tested who were accepted as having viral hepatitis. There were 60 patients below the age of 15 years, none of whom showed the antigen. Thus $21 \%$ of those over the age of 15 were antigen positive. The prevalence of HBAg did not depend on the interval between the testing of the first blood sample and the onset of the illness. There was no significant difference between patients tested during the first week (five $(12 \%)$ positive out of 43 ) and those tested in the first four weeks $(25(15 \%)$ positive out of 168$)$. The mean number of tests carried out during the first four weeks (1.5) was identical for the antigen-positive and antigen-negative groups. Six patients remained positive after the 12 th week and at the time of writing one had been positive for six months. The median period of antigenaemia was seven weeks (mean 8.5 weeks) in the 25 adequately followed antigen-positive patients who subsequently became negative. Blood was obtained for HBAg testing in $82 \%$ of the patients tested within four weeks of the onset of the illness and in $94 \%$ of those tested within seven weeks.

Of the 81 patients tested for HBAg and thought to have acquired their infection parenterally $18(22 \%)$ were positive The findings in the equivocal group were similar, four $(17 \%)$ out of 23 tested being $\mathrm{HBAg}$ positive, while a smaller proportion was found in the unknown group, $10(14 \%)$ out of 70 tested. None of the ingestion group was positive (table I).

In the parenteral group four of the 10 patients who had a nontherapeutic skin puncture were $\mathrm{HBAg}$ positive whereas 14 $(21 \%)$ of the 67 whose parenteral exposure was therapeutic 
showed the antigen. Four HBAg-negative patients had both therapeutic and non-therapeutic exposures. In the non-therapeutic group there were four drug addicts, two of whom were HBAg positive. Four had been tattooed, of whom two were positive.

There were more than five times as many men (27) as women (five) with the HBAg though the overall ratio of male (129) to female (86) patients tested was 1.5:1 (table II). Nearly half the males were in the parenteral group. The unknown group contained about equal numbers of males and females but the HBAg was found only in the males.

In the 20-39 age group there were nearly twice as many men as women (table III), and 19 of the 62 men ( $31 \%$ ) were $\mathrm{HBAg}$ positive compared with only four of the 35 women (11\%). This age group contributed two thirds (23 out of 32) of all the HBAgpositive patients. All but two of these antigen-positive patients fell into the parenteral or unknown groups (table I).

Half the patients in the ingestion and equivocal groups were under the age of 15 whereas only one in 7 of the parenteral and unknown groups were of this age (see table I). No patient under the age of 15 was found to have circulating HBAg.

Of the 69 patients admitted to hospital $14(20 \%)$ were $\mathrm{HBAg}$ positive, compared with $18(12 \%)$ of the 146 patients seen at home. Adult men (39 out of $95 ; 41 \%$ ) were more likely than women $(18$ out of $60 ; 30 \%$ ) to be admitted to hospital. Neither of these differences has reached statistical significance after one year of the survey.

There was a clear seasonal fluctuation in incidence of hepatitis. This was confined to the HBAg negative patients and showed peaks in the early spring and autumn. Apart from one outbreak in a housing estate there was no appreciable clustering of patients. None of the patients in this outbreak was $\mathrm{HBAg}$ positive, and 19 of the 32 affected were under the age of 15.

In the HBAg-positive patients the mean $( \pm$ S.D.) duration of clinical jaundice was significantly greater, $41.6 \pm 24.8$ days, than in those not showing the antigen, where it lasted for a mean ( \pm S.D.) of $24.3 \pm 21.5$ days ( $<<0.01$, using a $\chi^{2}$ test).

TABLE I-Relation of HBAg to Age and Epidemiological Group in 215 Patients Tested. Figures in parentheses are Numbers of Antigen-positive Patients

\begin{tabular}{c|c|c|c|c|c}
\hline Age & Ingestion & Parenteral & Unknown & Equivocal & Total \\
\cline { 1 - 2 } $0-4$ & 2 & 1 & 2 & 1 & 6 \\
$5-9$ & 21 & 8 & 5 & 6 & 40 \\
$10-14$ & 3 & 1 & 5 & 5 & 14 \\
$15-19$ & 1 & $12(1)$ & 7 & $3(2)$ & $23(3)$ \\
$20-29$ & 8 & $25(6)$ & $23(5)$ & $3(1)$ & $59(12)$ \\
$30-39$ & 3 & $21(9)$ & $10(1)$ & $4(1)$ & $38(11)$ \\
$40-49$ & 3 & $6(2)$ & $9(3)$ & 1 & $19(5)$ \\
$50-59$ & 0 & 5 & $6(1)$ & 0 & $11(1)$ \\
$60-69$ & 0 & 2 & 3 & 0 & 5 \\
\hline Total & 41 & $81(18)$ & $70(10)$ & $23(4)$ & $215(32)$ \\
\hline
\end{tabular}

TABLE II-Relation of HBAg to Sex and Epidemiological Group in 215 Patients Tested. Figures in Parentheses are Numbers of Antigen-positive Patients

\begin{tabular}{|c|c|c|c|c|c|}
\hline & Ingestion & Parenteral & Unknown & Equivocal & Total \\
\hline $\begin{array}{l}\text { Male } \\
\text { Female }\end{array}$ & $\begin{array}{l}21 \\
20\end{array}$ & $\begin{array}{c}56 \\
(15) \\
25 \\
(3)\end{array}$ & $\begin{array}{c}38 \\
(10) \\
32\end{array}$ & $\begin{array}{c}14 \\
(2) \\
9 \\
(2)\end{array}$ & $\begin{array}{c}129 \\
(27) \\
86 \\
(5)\end{array}$ \\
\hline Total & 41 & $\begin{array}{c}81 \\
(18)\end{array}$ & $\begin{array}{c}70 \\
(10)\end{array}$ & $\begin{array}{l}23 \\
(4)\end{array}$ & $\begin{array}{l}215 \\
(32)\end{array}$ \\
\hline
\end{tabular}

TABLE III-Relation of HBAg to Sex and Age in 215 Patients Tested. Figures in Parentheses are Numbers of Antigen-positive Patients

\begin{tabular}{c|c|c|c}
\hline Age & Male & Female & Total \\
\hline $0-4$ & 1 & 5 & 6 \\
$5-9$ & 24 & 16 & 40 \\
$10-14$ & 9 & 5 & 14 \\
$15-19$ & $13(2)$ & $10(1)$ & $23(3)$ \\
$20-29$ & $36(10)$ & $23(2)$ & $59(12)$ \\
$30-39$ & $26(9)$ & 7 & $38(11)$ \\
$40-49$ & $12(5)$ & 5 & $19(5)$ \\
$50-59$ & $6(1)$ & 3 & $11(1)$ \\
$60-69$ & 2 & $86(5)$ & $215(32)$ \\
\hline Total & $129(27)$ & & \\
\hline
\end{tabular}

\section{Discussion}

The results of the first 12 months of the three-year survey showed two salient features. Firstly, the prevalence of HBAg in patients with viral hepatitis was only $15 \%$ though a highly sensitive technique was used to test serial samples of serum. Secondly, there was a concentration of positive cases among men aged between 20 and 39 years (19 out of $62 ; 31 \%$ ).

Previous reports from West London (Cossart et al., 1969, Farrow et al., 1970) suggested that the prevalence of HBAg in sporadic hepatitis in the United Kingdom was in the region of $30-40 \%$. Both studies were of patients admitted to hospital, however, whereas we attempted to investigate all patients developing this illness irrespective of their place of care. Our data suggested that the higher prevalence of $\mathrm{HBAg}$ in hospital patients might be due to the larger number of adult males admitted.

The pilot study had shown the vital importance of full collaboration with the general practitioners and they were therefore involved in the three-year survey through discussions at meetings held for this purpose both before and during the survey. A domiciliary diagnostic service was provided on all patients referred by family doctors, who reciprocated by informing the survey team of possible preicteric cases and with early notifications. As a result of this collaboration most sera were taken early in the illness.

The proportion of positive results showed no significant difference throughout the first four weeks, nor was there a significant difference between the mean number of tests in the HBAg positive and negative patients. The proportion of patients tested in the two groups was the same. Though we cannot exclude the possibility of clearance of the antigen before the onset of jaundice other studies suggest that this is unusual (Krugman and Giles, 1970).

The 20-39 age groups accounted for 19 of the 27 positive men and all but one of the five positive women (table III). The predominance of young adults was not explained by drug addiction, because only four patients in the whole survey admitted to this practice. The possibility of venereal transfer has been raised by Mirick and Shank (1959), Hersh et al. (1971), and Fulford et al. (1973).

The preponderance of males has been noted previously (reviewed by Zuckerman, 1972) and may be due to a sex difference in susceptibility to infection. It is of interest that nearly half the HBAg positive patients in this survey were men with a history of parenteral exposure though most of these exposures involved the use of disposable equipment -for instance, in vaccinations, inoculations, and dental local anaesthetics. One third of the children (under 15 years) had had a skin puncture under similar conditions and none of them was $\mathrm{HBAg}$ positive.

Fewer children than adults were tested for $\mathrm{HBAg}-60$ out of $86(70 \%)$ as compared with 155 out of $163(95 \%)$. This could lead to an underestimate of the proportion of children in this survey. Whereas only 60 of the 215 patients tested $(28 \%)$ were under the age of $1586(35 \%)$ of the 249 patients seen with hepatitis were children. Furthermore, we cannot exclude the possibility that the HBAg might have been present in some of the 26 children not tested.

During this initial period of the survey there was a brief localized outbreak of hepatitis mainly affecting children who, in our experience, are HBAg negative. Such outbreaks could have a considerable effect on the prevalence of $\mathrm{HBAg}$ during a relatively short period of observation. Analysis of the threeyear figures should clarify the effect of such outbreaks on the prevalence of HBAg viral hepatitis in urban communities in this country.

This survey is being financed by the Research Division of the Department of Health and Social Security to whom we are grateful for support. We thank the survey team, Dr. S. R. Vinden, Miss P. A. Saunders, H. V., and Mrs. M. Ellis, and Dr. M. Wilkinson of Hounslow Health Department, Dr. A. M. Nelson, and Dr. M. James 
of Richmond Health Department, and Dr. I. Taylor and Dr. T. Sebestyen of Ealing Health Department. We are indebted to all the general practitioners in the three boroughs for their close co-operation, so vital to the survey. We thank Dr. Hillas G. Smith of Neasden Hospital, Dr. P. L. N. Baly of St. John's Hospital, Uxbridge, and Dr. J. Vahrman of Western Hospital, Fulham, who kindly provided access to patients, Mr. T. G. Marris for statistical advice and help, and Dr. R. A. Dale, consultant clinical biochemist, West Middlesex Hospital, for all the biochemical data.

Requests for reprints should be sent to Dr. J. S. Stewart.

\section{References}

Cossart, Y., et al. (1969). British Medical fournal, 3, 755.
Farrow, L. J., et al. (1970). British Medical fournal, 2, 693.

Fulford, K. W. M., et al. (1973). Lancet, 1, 1470.

Hersh, T., et al. (1971). New England fournal of Medicine, 285, 1363.

Krugman, P., and Giles, J. P. (1970). Fournal of the American Medical Association, 212, 1019.

Malloy, H. T., and Evelyn, K. A. (1937). Fournal of Biological Chemistry, 119,481 .

Marsh, W., Fingerhut, B., and Kirsch, E. (1959). Clinical Chemistry, 5, 119. Mirick, G. S., and Shank, R. E. (1959). Transactions of the American Clinical and Climatological Association, 71, 176.

Mohun, A. F., and Cook, I. J. Y. (1957). Fournal of Clinical Pathology, 10, 394

Reed, W. D., ot al. (1973). Lancet, 2, 690

Ross, C. A. C., and McMichael, S. (1970). Lancet, 2, 61.

World Health Organization (1973). Viral Hepatitis, Technical Report Series, No. 512. Geneva, W.H.O.

Zuckerman, A. J. (1972). Hepatitis-associated Antigen and Viruses, p. 164. Amsterdam, North Holland Publishing.

\title{
DDAVP in Treatment of Vasopressin-sensitive Diabetes Insipidus
}

\author{
M. K. WARD, T. RUSSELL FRASER
}

British Medical fournal, 1974, 3, 86-89

\section{Summary}

In 11 patients with vasopressin-sensitive diabetes insipidus the effectiveness of the vasopressin analogue 1-desamino-8D-arginine vasopressin (DDAVP) for controlling diabetes insipidus has been compared with that of lysine vasopressin. DDAVP in equivalent intravenous dosage has been found to be at least as potent and to have a more prolonged action, lasting 13-22 hours instead of 1-2 hours. Twice-daily intranasal DDAVP effected satisfactory control in all these patients, without side effects, and all the patients preferred this to their previous treatment. Single daily intramuscular injections of DDAVP were found to offer excellent control for any subject unable to manage intranasal administration.

\section{Introduction}

Improvements in the treatment of diabetes insipidus (D.I.) have obviated the need for injections in mild vasopressinsensitive cases by the use of either chlorpropamide (Wales and Fraser, 1971) and related drugs (Arduino et al., 1966) or lysine vasopressin (LVP) nasal sprays (Dashe et al., 1964). Neither of these treatments, however, can control the more serious cases satisfactorily. The recent synthesis of an analogue of arginine vasopressin (AVP), 1-desamino-8-Darginine vasopressin (DDAVP) (Vara et al., 1968), has produced an agent administrable intranasally which has the full antidiuretic effects of AVP with minimal vasopressor activity and scarcely any side effects in the dose range required (Anderson and Arner, 1972; Edwards et al., 1973). DDAVP has been found to have a greater antidiuretic effect and a longer duration of action than the natural hormone AVP (in man) or LVP (in some other species) and has been shown to be effective in controlling vasopressin-sensitive diabetes insipidus

\footnotetext{
Bndocrine Unit, Department of Medicine, Royal Postgraduate Medical School, London W12 OHS

M. K. WARD, M.B., M.R.C.P., Registrar
}

(Anderson and Arner, 1972). We report here a comparison with LVP showing the more prolonged action of DDAVP, it seffective control of a wide range of cases of vasopressin sensitive diabetes insipidus on a twice-daily intranasal regimen, and its potential usefulness in controlling such cases by single daily injections when necessary.

\section{Patients}

Altogether 11 patients were studied (table I). All had previously been investigated and diagnosed as having vasopressinsensitive diabetes insipidus either alone or with associated pituitary lesions. None of the patients were satisfied with their immediate previous therapy (table I). On their current regimens all had some persisting symptoms of mild thirst, polyuria, and nocturia. Six patients had had trials with either clofibrate or chlorothiazide or carbamazepine carried out by us or at other hospitals. Five patients previously treated with chlorpropamide $250-500 \mathrm{mg}$ daily had had to have the drug withdrawn or the dosage reduced because of hypoglycaemia, and one patient had had an "Antabuse" effect with alcohol. Five patients were maintained on vasopressin tannate in oil (5 IU intramuscularly on alternate days) with or without LVP nasal spray supplementation. One patient (case 2) who had been maintained on posterior pituitary nasal snuff for 10 years had not had an undisturbed night's sleep or been free of rhinitis throughout that time.

\section{Method}

Previous therapy was discontinued (five days for those on chlorpropamide and one to three days for those receiving vasopressin preparations). Thereafter all the patients' 24hour urine volumes were measured, initially when off all previous treatment and later while on maintenance intranasal DDAVP.

Before establishing the patients on maintenance therapy a series of acute studies were performed of their diuretic response both uncontrolled and after LVP or DDAVP, either as inpatients or as outpatients. Firstly, a full diuresis was ensured by an oral water load of $20 \mathrm{ml} / \mathrm{kg}$ given over 30 minutes, after which they were urged to drink an amount at 